\title{
Partial reduction of air pollution in India during COVID-19 lockdown
}

\begin{abstract}
India has been struggling with pollution with the increase in population day by day. In fact, as per the World Economic Forum in February 2020, India became the sixth out of 10 world's most air-polluted cities. On March 24, 2020. India has declared initially lockdown 1 i.e. 21 days amid the extent of the dangerous Corona Virus (Covid-19), it is the largest lockdown in the world encompassing 130 crores of population. With that several people were at their houses, traffic has been drastically decreased, construction and factories are stopped for a while during this lockdown, foremost to a significant reduction in smog as well as the air pollution. Given that, we have studied the environmental pollution in metropolitan cities of India during the first lockdown. The pollution and smog in the air were dropped drastically in all metro cities because of the lockdown in India.
\end{abstract}

Volume 8 Issue 2 - 202I

\author{
Gonamanda Satya Sree, Kapilavayi Venkata \\ Basava Ranjitha, Boggu Jagan Mohan Reddy \\ Department of Chemistry, Adikavi Nannaya University, India
}

Correspondence: Boggu Jagan Mohan Reddy, Department of Chemistry, Adikavi Nannaya University, Rajamahendravaram533296, India, Email drbjaganredd@gmail.com

Received: March II, 202I | Published: March 23, 202 I

Keywords: covid-19, air quality, India, lockdown, air pollution, reduction

\section{Introduction}

In India, Pollution has turned out to be a great issue of debate at every level and mainly the air pollution due to the anthropogenic activities enhancement includes fossil fuels burning i.e. coal, natural gas, and oil to power motor vehicles and industrial processes. ${ }^{1}$ Different harmful chemicals are free into the air, like carbon monoxide (CO), Sulphur dioxide $\left(\mathrm{SO}_{2}\right)$, carbon dioxide $\left(\mathrm{CO}_{2}\right)$, nitrogen oxides $\left(\mathrm{NO}_{\mathrm{x}}\right)$, and other minute solid particles containing lead from gasoline additives known as particulates by burning of the harmful fossil fuels. ${ }^{2}$ In India, Urbanization is rapid around the main cities. Due to the migration of rural people, population growth has accelerated in cities. More rise in industrial tasks, and high population both floating and endemic, vehicular population, etc. has directed to a continuous rise in environmental complications like Air pollution. More than 80 percent of people in this world existing in urban areas, showing air pollution is wide-open to air purity levels that surpassed the World Health Organization (WHO) limits. ${ }^{3}$

The value of air in the major metropolitan cities like Delhi, Visakhapatnam, Nagpur, Mumbai, Chennai, and Kolkata are notorious for being at the worst level in this world, is now in a "healthy and safe zone" owing to the 21-day first lockdown to resist the increase of Covid-19 spread. The remaining metropolitan and other tier-2 cities too were showing a similar trend. Starting from 25 March 2020, India has sheltered down all types of company offices, educational institutes, movie halls, shopping malls, markets, and non-essential service providers. All types of public and private transportation modes such as international flights, metro trains, inter-state trains and buses, intrastate trains and buses, and domestic flights intended for civilian movement are completely stopped. A reading value less than 50 indicates good and fair air quality, between 100 and 200 shows the moderate quality and air purity level is above 200 , and then the air quality is very poor. High-intensity air pollution initiates remarkable public health issues ${ }^{4}$ in particular chronic respiratory diseases, breath shortness, acute asthma, and pneumonia, etc. ${ }^{5}$ Therefore, in this article, we report the climate variations in metropolitan places like Delhi, Ahmadabad, Visakhapatnam, Nagpur, Mumbai, Bangalore, Chennai, and Kolkata during the first lockdown in India.

\section{Sources of air pollution}

Traffic: The usage of cars number on India's roads has been increasing and doubling every 8 to 10 years and it is costing the country's pollution. Every year, the country is experiencing about 1,20,000 deaths due to more traffic fatalities, greater than other countries. And especially, traffic crowding in Bangalore, the capital of Karnataka alone rates the city $5 \%$ approximately of its economic yield. By the end of last decade, $65 \%$ vehicles of 5 million two-wheelers ran on petrol in India. Across major places in India, nearly 1000 tons of pollutants are released into the atmosphere daily of which $50 \%$ is from vehicle exhausts. By the completion of 2035, the overall Indian fuel demand will be six times the fuel demand recorded in the year 2005 has been estimated. Moreover, most people used bigger vehicles which are in general compact, moderate in size, and require good fuel. By the completion of $2030-31$, it is estimated that if $50 \%$ of India's fuel efficiency is achieved by studying energy policies then only India can save up to $65 \%$ of its total energy usage \& decrease $\mathrm{CO}_{2}$ emissions equal to eradicating seven million of four-wheelers. Through the transport sector, about $15 \%$ of total $\mathrm{CO}_{2}$ is released into the air in India. It is observed that a $6 \%$ rise in the quantity of emission $\mathrm{CO}_{2}$ occurs per year. ${ }^{6}$

Industrial wastes and thermal plants: Due to quick and rapid growth in industrialization and the establishment of multiple factories, a dense of industries has been running from past discharging chief pollutant gases $\mathrm{SO}_{2}$ and $\mathrm{NO}_{2}$. It is noticed that Mathura-based oil refineries are causing the deterioration of the Taj Mahal and other monuments at Fatehpur Sikri. Together with industries there are other numerous thermal power plants where consumption of coal is in millions of tonnes and the main pollutants released are hydrocarbons, fly ash, S02 along remaining gases. ${ }^{7}$

Anthropogenic activities: Apart from major sources, the following actions contribute to the chief role in air pollution increase due to burning of wastes crop by farmers, usage of stoves, incinerators, refrigerators, and aerosol sprays. Production of methane owing to deposition of trashes and wastes in landfills, authentication of nuclear weapons by army personnel, dust particles produced from 
natural sources, uncertain volcanic activities producing high content of fumes, ash, uncertain forest fires, and decomposition of animals leading to the production of methane.

\section{Air pollutants}

Particulate matter $\left(\mathrm{PM}_{2.5}\right.$ and $\left.\mathrm{PM}_{10}\right)$ : Grit, Fly ash, dust, and Suspended particulate matter (SPM) obtained from industries and other hydroelectric power plants. It includes spores of fungal, bacterial cells, and also pollen in the air. $\mathrm{NO}_{2} \mathrm{SO}_{2}$ and $\mathrm{NH}_{3}$ : Released and free from power plants including with all industrial units.

CO: Mainly released from all vehicles and also burning of fossil fuel.

\section{Air quality assessment during the lockdown in India}

The standards of air quality are the basic foundation that provides a legal framework for the control of air pollution. To understand the complete perfection in air quality, Air Quality Index (AQI) was computed. AQI represents the grade of air quality and alters complex air quality of various contaminants data into a specific color. The air quality standard denoted by regulatory authority has governed a standard of air quality. ${ }^{8}$ In context to develop the air quality standards, need to supply rational to public health defense from adverse effects of bad air quality and to minimize exposure to air contaminants, hence local authorities or heads, direct nationals need to control pollution verdicts. With these objectives, CPCB notified ${ }^{9}$ new set of Indian National Air Quality Standards (INAQS) for 12 parameters [carbon monoxide $(\mathrm{CO})$, sulfur dioxide $\left(\mathrm{SO}_{2}\right)$, nitrogen dioxide $\left(\mathrm{NO}_{2}\right)$, particulate matter $(\mathrm{PM})$ of below 2.5 microns size $\left(\mathrm{PM}_{2.5}\right), \mathrm{PM}$ of below the size of 10 microns $\left(\mathrm{PM}_{10}\right)$, Ammonia $\left(\mathrm{NH}_{3}\right)$, Ozone $\left(\mathrm{O}_{3}\right)$, Benzo(a)Pyrene (BaP), Arsenic (As), Lead $(\mathrm{Pb})$, Benzene $\left(\mathrm{C}_{6} \mathrm{H}_{6}\right)$, and also Nickel (Ni)].

The details of AQI are freely accessible, and briefly explained and recapitulated here. AQI comprises $\mathrm{PM}_{10}, \mathrm{PM}_{2.5}, \mathrm{O}_{3} \mathrm{NO}_{2}, \mathrm{SO}_{2}, \mathrm{CO}, \mathrm{Pb}$, and $\mathrm{NH}_{3}$ of which fewer concentrations of three contaminants should be accessible with at least either $\mathrm{PM}_{2.5}$ or $\mathrm{PM}_{10}$. The concentrations are transformed on a scale of $0-500$. The sub-index AQI (AQIi) for each pollutant (i) is calculated by using equation (1)

$$
\mathrm{AQIi}=\mathrm{INHI}-\mathrm{INLO} / \mathrm{BHI}-\mathrm{BLO} \times(\mathrm{Ci}-\mathrm{BLO})+\mathrm{INLO} \mathrm{Eq}(1)
$$

Where $\mathrm{Ci}$ is the pollutant concentration, $\mathrm{BHI}$ and BLO are breakpoint concentrations greater and smaller to $\mathrm{Ci}$, and INHI and INLO are corresponding AQI values. The total AQI is the greatest $\mathrm{AQIi}$, and the respective pollutant is dominating pollutant. The AQI is categorized into five divisions: good, Satisfactory, Modest (Moderate), Poor, very poor, and severe depending on AQI level falls between $0-50,51-100,101-200,201-300,301-400$, and 401-500, respectively. The average AQI for October 2018 was observed as 285 and it was decreased to 238 in October 2019 (Table 1). Air Quality Index of 201300 shows "poor" quality of air, according to the Central Pollution Control Board (CPCB)

However, the question is that whether this good air run is sustainable once the lockdown ends. Global climate transform communal has, for example, warned besides looking at "silver lining," highlights that lockdowns won't take away the necessity for consistent policy modify to mend air quality level and to struggle against climate change. Awareness of air pollution levels daily is significant to the citizens, mainly for the people who suffer from illnesses caused and affected by the contact to air pollution. Further, the success and the victory of a nation on the improvement of air quality in the environment depends on the support given by the citizens who should be well informed about regional and national air pollution consequences and problems and also about the advancement of mitigation efforts. Thus, easy yet active communication of the quality of air is significant. The concept of AQI that converts concentration of air pollution-associated parameters (e.g. $\mathrm{SO}_{2}, \mathrm{PM}, \mathrm{CO}, \mathrm{NO}$, etc.) into a set of numbers or single numbers are extensively utilized for air quality communication and making decisions in many other countries. ${ }^{10}$

Table I Number of days in each category

\begin{tabular}{lll}
\hline Air quality & Oct-18 & Oct-19 \\
\hline Good & None & None \\
Satisfactory & None & 2 \\
Moderate & 3 & 8 \\
Poor & 17 & 14 \\
Very Poor & 10 & 14 \\
Severe & 1 & 3 \\
Average AQI & 285 & 238 \\
\hline
\end{tabular}

The nationwide 'Janta Curfew' on March 22 $2^{\text {nd }}, 2020$ followed by the first 21-day lockdown to defeat the coronavirus burst and its spreading have led to a more significant drop in pollution all and around the country with 91 major cities footage air quality level in the category of 'good' and 'satisfactory'. Moreover, restrictions of the transport and closure and shutting of industries have helped to lessen the level of pollution in the nation. As a result of tight travel restrictions in both public and private transportation and the complete shutdown of non-essential activities in which includes air polluting sectors, the improvement of air quality level has been recorded in cities and towns across the nation. On March 21, 2020 (a day before the Janata Curfew) a total of 54 cities recorded 'good' as well as 'satisfactory' air quality while on March $29^{\text {th }}, 2020$ as many as 91 cities recorded minimal and less pollution levels. Since the first lockdown was imposed in the nation, and unnoticeable improvement was observed in the air quality everywhere in the country due to the reduction of local pollutants produced and generated due to vehicular traffic and construction activities.

An Air Quality Level (AQI) amid 0 to 50 is considered as good quality, 51 to 100 satisfactory quality level, 101 to 200 moderate levels, 201 to 300 poor quality, 301 to 400 as poor quality, and 401 to 500 severe and adverse quality. AQI is the valuation of the quality of air by taking considerations into several factors. The lesser the value of AQI is considered to be the better quality. On the day of 'Janata Curfew', as a result of the grouping of no vehicles on the road, working and functioning of only a few important and needed commercial units and prevailing conditions of weather, a significant and noticeable reduction was noted for NOx (nitrogen oxide) and $\mathrm{PM}_{10}$ levels. ${ }^{11}$ Overall, the effect of Janata Curfew showed the general change and improvement in air quality among the nation with the quantum of perfection being diverse based on regional or local involvement sources, however, the regional involvement was largely reduced and absent. Already, the data shows that the main cities are showing recording much lesser levels of harmful and hazardous microscopic particulates matter known as $\mathrm{PM}_{2.5}$, and of nitrogen dioxide, which is released by the vehicles and also the power plants. ${ }^{12}$

During the initial three weeks of March, the average level of nitrogen dioxide was declined by about 40 to $50 \%$ in the main cities of 
Pune, Mumbai, and Ahmadabad, when equated to the same period in the last before years i.e. 2018 and 2019. Fossil fuel reduced emissions because of the restricted transportation and slowdown in many other emissions-related activities are slowly reduced the air pollutants and pollution in the environment. However, India has recorded good levels of air quality in major metropolitans such as Delhi, Chennai, Nagpur, Kolkata, Visakhapatnam, Mumbai, Ahmadabad, and Bangalore and the results were presented in Figures $1 \& 2$.

A significant decrease trend was observed in the air pollution level of metropolitan cities in India during the lockdown, a dominant change noticed in Delhi. For instance, the finer particulate matter was decreased in April (44.2) compared to March 2020 (53.9) that signifies the air quality is increased in April. The minimum PM2.5 was found to be 19.27 on the day immediately after the lockdown was announced (27 March 2020). Besides, NOx also exhibited less concentration in April (30.3 ppm) than in March 2020 (92.1 ppm) as presented in Table S1 in ESI. Noticed that clear change was obtained prior and later lockdown in Fig 3, clear sky without any disturbances which signifies the fallen air pollution. Among the peak, four metros are Delhi, Chennai, Kolkata, and Mumbai, AQI in Delhi drastically fallen from 300 (21 $1^{\text {st }}$ March 2020) to 40 (24 ${ }^{\text {th }}$ March 2020). Similar to that in Mumbai, AQI was recorded the highest (306) on $21^{\text {st }}$ March, and the lowest (36), on March 22. As shown in Table 2, the highest AQI (191) in Kolkata was reported before lockdown predominantly during last week and the lowest (33) was seen on March 23. A similar trend was observed in Chennai air quality, the highest AQI (274) was seen on $22^{\text {nd }}$ March, and the least AQI (25) on $21^{\text {st }}$ and $25^{\text {th }}$ March 2020 (Figure 3).

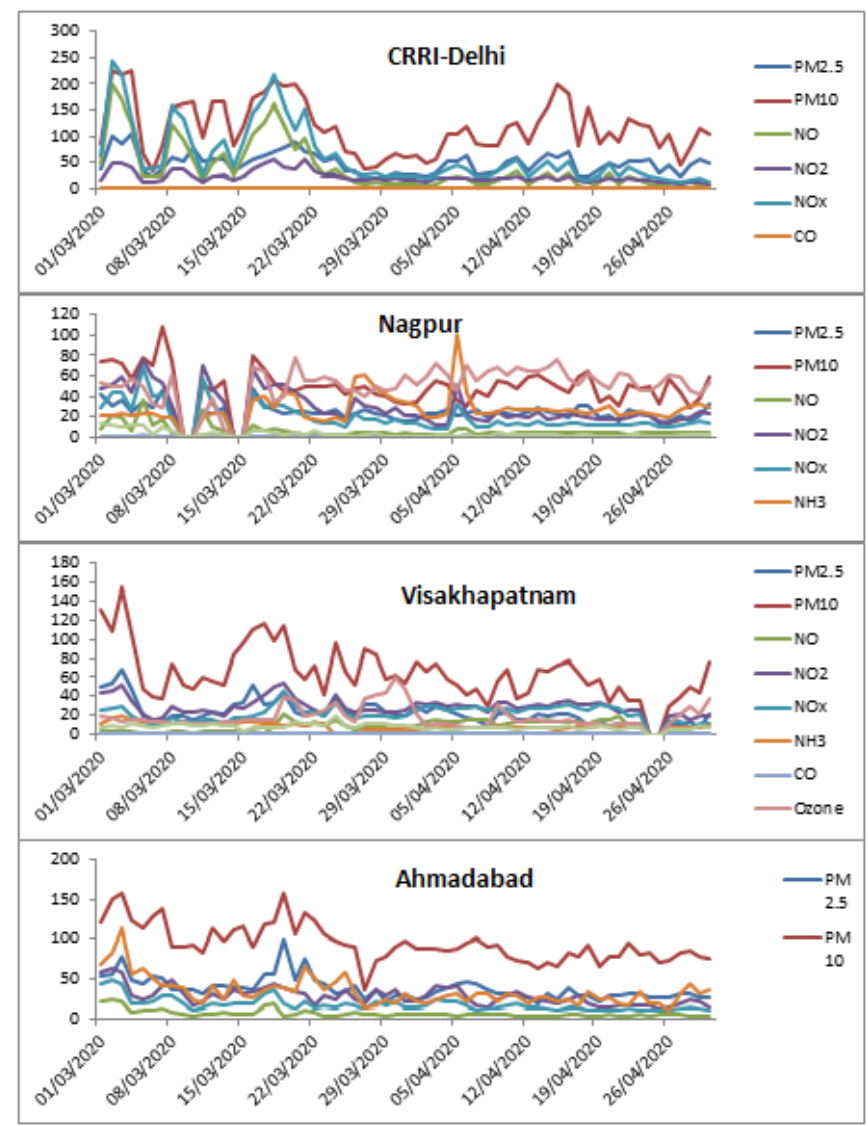

Figure I Air quality parameters in Delhi, Nagpur, Visakhapatnam, and Ahmadabad during March to April 2020.

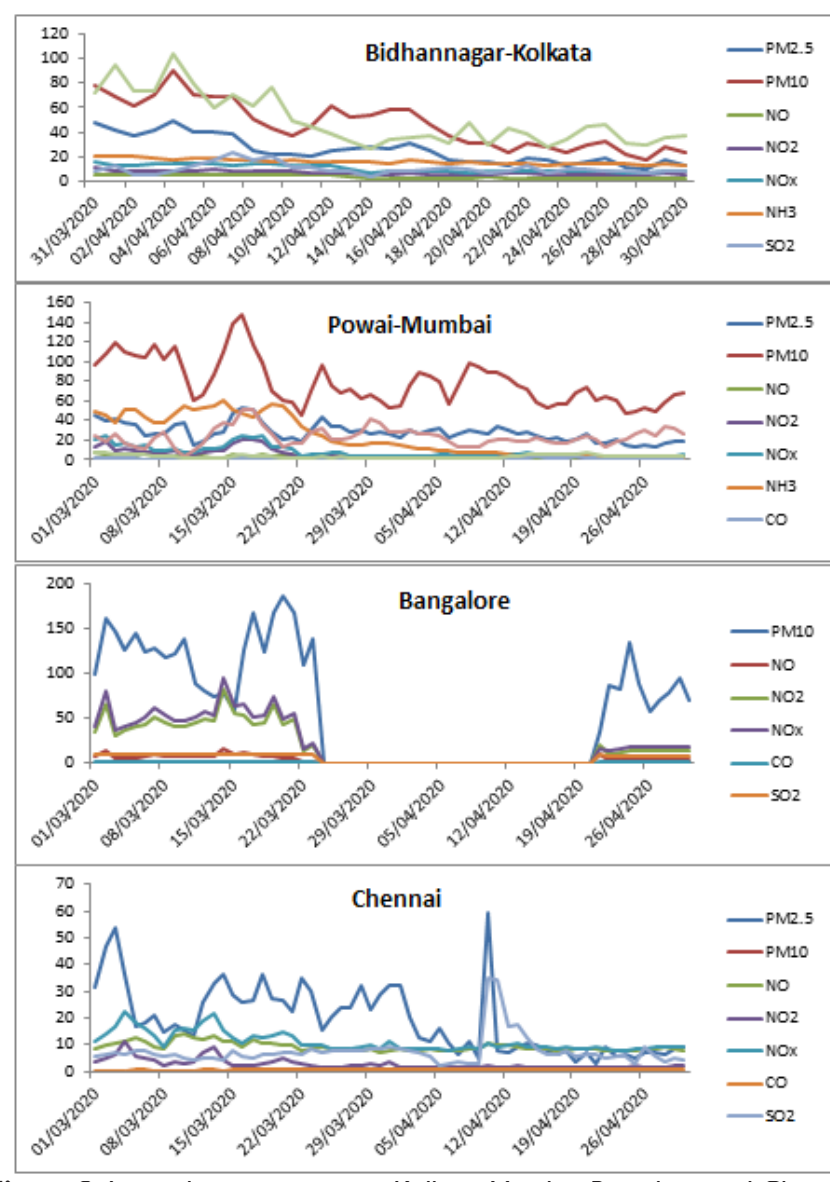

Figure 2 Air quality parameters in Kolkata, Mumbai, Bangalore, and Chennai during March to April 2020.

Table 2 Top 5 place with the highest and lowest AQI as of 4 pm on March 24

\begin{tabular}{ll}
\hline Lowest AQI & Highest AQI \\
\hline Chandigarh -35 & Great Noida-178 \\
Jalandhar-38 & Bulandshahr-184 \\
Ludhiana-39 & Faridabad-187 \\
Amaravathi-4I & Lucknow-204 \\
Khanna-45 & Muzaffarpur - 273 \\
\hline
\end{tabular}

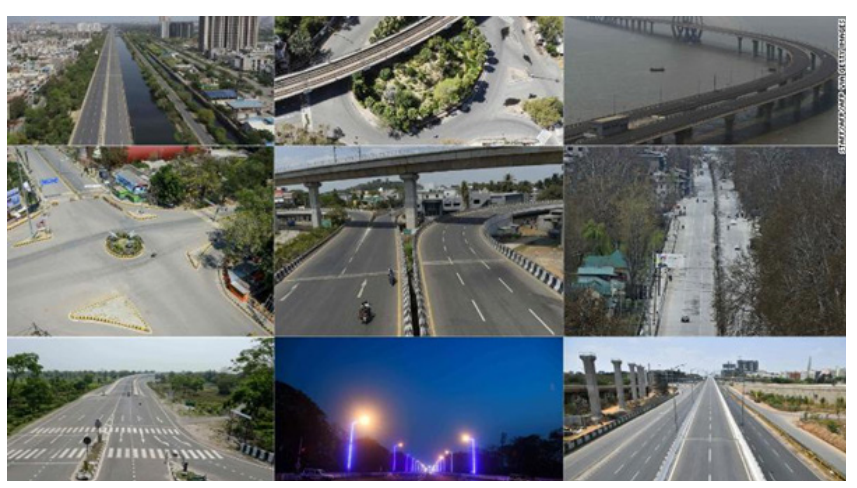

Figure 3 These pictures were taken on March 25 show deserted streets across India. The top row, from left to right, shows Ghaziabad, New Delhi, Mumbai. The middle row, left to right, is Allahabad, Chennai, and Kashmir. The bottom row, left to right, depicts Siliguri, Kolkata, and Bangalore. 


\section{CO2 emissions reduced $30 \%$ in April month}

In the financial year by March-end, estimated that the emissions of $\mathrm{CO}_{2}$ cut down by $30 \mathrm{~m}$ tons of $\mathrm{CO}_{2}\left(\mathrm{MtCO}_{2}, 1.4 \%\right)$ using aforementioned indicators for the consumption of coal, gas, and oil, is probable the first annual decrease in last four decades. Furthermore, emissions cut down by approximately $15 \%$ in March that remarkably decreased (30\%) in April 2020. During April, the power-related sectors that contributed air pollutant emissions were calculated from each day generation data. This assumption seems to be oil consumption tremendously falls as much in April as at the end of March, which signifies that more conservative as the lockdown in the nation is further continues till the end of the month, and the projected gas consumption falls about $15-20 \%$. Over the last year, $\mathrm{CO}_{2}$ emissions along with the air pollution levels have been declined. More recently, during the first national lockdown over the country, the blue sky has created is a sense of optimism towards the public and policymakers represents that the air in India can be hygienic and maintained good quality if appropriate and required steps are adopted. ${ }^{13}$ Since there are more abundant sources of pollution includes transport, industry, and power stations are mainly responsible for significant shares of the country's $\mathrm{CO}_{2}$ output, any strengthening of air quality standards or their implementation would have knock-on effects on emissions.

Because of this, the Ministry of Environment has launched a program namely National Clean Air Program (NCAP) in last year to control public pressure. The main aim of NCAP is to diminish the pollution level of particulate matter over 102 cities by the amount of 20 to $30 \%$ by the year 2024 . The NCAP program also stated the National ambient air quality standards (NAAQS) of India which needs further revision. Implementation of NCAP policies is safe and better to maintain healthy air. However, the latest experience of cleaner air which is the drastic drop in pollution levels of air due to pandemic COVID-19 lockdown has started the conversations to the strengthening of NAAQS over the public, academics, research institutes, and environmental organizations. ${ }^{14}$ As a result in return, the poor quality of air and smog in India could be supposed to generate a stronger public response. WHO guidelines and there is more evidence of health impacts of air pollution being reported even at low concentrations of pollutants.

\section{Conclusion}

In conclusion, the recent experience of cleaner air and the drastic drop in pollution levels due to coronavirus (COVID-19) have started these conversations to strengthen the NAAQS among the public, research institutes, and civil society organizations. As a result, the poor quality of air and smog in India can be predictable to generate a sturdy public response. There is drastic variation in air quality was seen before and after the lockdown in India. Up to three weeks after lockdown, air pollution levels dropped to the ground due to most of the people at home, restrictions of the transport and closure, and shutting of industries helped to lessen the level of pollution in the nation. Implementation of NCAP policies is required to safely and better maintain air quality.

\section{Acknowledgments}

The authors sincerely express their gratitude to Central Pollution Control Board (CPCB), India for real-time data. G Satya Sree says thanks to Andhra Pradesh Pollution Control Board (APPCB) for APPCB/RF/2018-19/07.

\section{Conflicts of interest}

Authors declare that there is no conflict of interest.

\section{Funding}

None.

\section{References}

1. Sharma S, Zhang M Anshika. Effect of restricted emissions during COVID-19 on air quality in India. Sci Total Environ. 2020;728:138878.

2. Kumar DSS. Air pollution in Visakhapatnam- an overview. Int $J$ Civil Engg. 2013;2(4):11-14.

3. Garaga R, Sahu SK, Kota SH. A review of air quality modeling studies in India: local and regional scale. Current Pollution Reports. 2018;4:59-73.

4. Dholakia HH, Purohit P, Rao S, et al. Impact of current policies on future air quality and health outcomes in Delhi, India. Atmos environ. 2013;75:241-248

5. Rizwan SA, Nongkynrih B, Gupta SK. Air pollution in Delhi: its magnitude and effects on health. Indian journal of community medicine: official publication of Indian Association of Preventive \& Social Medicine. 2013;38(1):4

6. Beig G, Sahu SK. SAFAR-High Resolution Emission Inventory of MegaCity Delhi-2018. In: BeigG, Sahu SK, editors. MoES, New Delhi; 2018.

7. Solaymani S. $\mathrm{CO}_{2}$ emissions patterns in 7 top carbon emitter economies: the case of the transport sector. Energy. 2019;168:989-1001.

8. Kumar P, Gulia S, Harrison RM, et al. The influence of odd-even car trial on fine and coarse particles in Delhi. Environ Pollu. 2017;225:20-30.

9. CPCB: Central Pollution Control Board. Guidelines for the Measurement of Ambient Air Pollutants VOLUME-ii. Central Pollution Control Board, Ministry of Environment, Forest and Climate Change. 2011. 62 p.

10. Shen F, Zhang L, Jiang L, et al. Temporal variations of six ambient criteria air pollutants from 2015 to 2018, their spatial distributions, health risks, and relationships with socioeconomic factors during 2018 in China. Environ Int. 2020;137:105556.

11. Zhang H, Hu J, Kleeman M, et al. Source apportionment of sulfate and nitrate particulate matter in the Eastern United States and effectiveness of emission control programs. Sci Total Environ. 2014;490:171-181.

12. Wang $\mathrm{P}$, Guo $\mathrm{H}, \mathrm{Hu} \mathrm{J}$, et al. Responses of $\mathrm{PM} 2.5$ and $\mathrm{O}_{3}$ concentrations to changes of meteorology and emissions in China. Sci Total Environ. 2019;662:297-306.

13. Peters GP. Carbon dioxide emissions continue to grow amidst slowly emerging climate policies. Nat Clim Change. 2020;10:3-6.

14. Mohan M, Kandya A. An analysis of the annual and seasonal trends of air quality index of Delhi. Environ monitor and assess. 2007;131(1-3):267277. 